\title{
Endoscopic Ultrasound-Guided Fine Needle Aspiration and Biopsy in Gastrointestinal Subepithelial Tumors
}

\author{
Gyu Young Pih and Do Hoon Kim \\ Department of Gastroenterology, Asan Medical Center, University of Ulsan College of Medicine, Seoul, Korea
}

The incidence of asymptomatic and incidentally found upper gastrointestinal subepithelial tumors (SETs) is increasing with the implementation of national cancer screening and the development of high-resolution endoscopy in Korea. However, endoscopy alone cannot be used to determine whether SETs are benign or malignant. Endoscopic ultrasound (EUS) is used to further characterize these lesions through the examination of their layered structure, internal echogenicity, size, and relationship to the extramural structure. These provide additional information on whether the lesion is benign or malignant. Nevertheless, the sensitivity and specificity of EUS alone in predicting malignancy is unsatisfactory. Recent guidelines have recommended deciding the timing of EUS-fine needle aspiration and biopsy (EUS-FNA/B) for SETs based on tumor size, malignant features on endoscopy, and high-risk features on EUS. The diagnostic accuracy of EUS-FNA/B is reportedly influenced by factors including needle size, number of needle passes, use of suction, use of a stylet in the needle assembly, fanning technique, availability of an on-site cytopathologist, and experience of the endosonographer. Therefore, according to the characteristics of the SETs, various subsequent methods and techniques should be appropriately employed to improve the diagnostic yield of EUS-FNA/B. Clin Endosc 2019;52:314-320

Key Words: Endoscopic ultrasound; Subepithelial tumor; Stomach

\section{INTRODUCTION}

Currently, incidental findings of gastrointestinal (GI) subepithelial tumors (SETs) are increasing because of the implementation of national cancer screening endoscopy and the development of high-resolution endoscopy in Korea. The prevalence of gastric SETs reportedly ranges from $0.36 \%$ to $1.7 \%{ }^{1,2}$ A decision is required at the time of discovery on whether the tumor should be further evaluated or if it can be observed with periodic follow-up. Indefinite decisions for SETs can result in poor cost-effectiveness with unnecessary endoscopy and emotional distress in patients, leading to poor

Received: May 15, 2019 Revised: June 24, 2019

Accepted: June 25, 2019

Correspondence: Do Hoon Kim

Department of Gastroenterology, Asan Medical Center, University of Ulsan College of Medicine, 88 Olympic-ro 43-gil, Songpa-gu, Seoul 05505, Korea Tel: +82-2-3010-3193, Fax: +82-2-476-0824, E-mail: dohoon.md@gmail.com ORCID: https://orcid.org/0000-0002-4250-4683

(c) This is an Open Access article distributed under the terms of the Creative Commons Attribution Non-Commercial License (http://creativecommons.org/ licenses/by-nc/3.0) which permits unrestricted non-commercial use, distribution, and reproduction in any medium, provided the original work is properly cited. compliance. Although endoscopic ultrasound (EUS), computed tomography (CT), and bite-on-bite biopsy may help in accurate diagnosis, these methods cannot always be performed for all SETs.

EUS is used to further characterize lesions through the examination of their layered structure, internal echogenicity, size, and relationship to the extramural structure. These provide additional information on whether the lesion is benign or malignant. However, although there are lesions with typical EUS findings, such as lipomas, duplication cysts, and heterotopic pancreas, ${ }^{3}$ hypoechoic lesions originating from the fourth layer, such as leiomyomas, gastrointestinal stromal tumors (GISTs), and schwannomas, are difficult to distinguish with EUS alone. A previous study reported that the sensitivity and specificity of EUS in predicting malignancy was $64 \%$ and $80 \%$, respectively. ${ }^{4}$ Furthermore, the interpretation of the EUS image is dependent on the operator. Therefore, tissue acquisition through EUS-guided fine needle aspiration and biopsy (EUS-FNA/B) is needed for further differential diagnosis. EUS-FNA/B has the advantage of having the capability of visualizing the subepithelial layer, as well as reaching ad- 
jacent organs located in a difficult area to be aspirated by the previous endoscopic tissue acquisition modalities. In addition to its minimal invasiveness, EUS-FNA/B is preferred over CT-guided biopsy because it does not induce radiation and enables real-time visualization of the needle tip. However, it has limitations in aspect of difficulty in visualizing the needle tip clearly and consistently and interference of the image by bowel gas. We reviewed the indications for EUS-FNA/B in gastric SETs and the methods that can be used to increase the diagnostic yield.

\section{INDICATION}

The basic principle of EUS-FNA/B is to obtain information that can affect the patients' treatment. EUS-FNA/B should be performed when the choice of treatment can be changed depending on the tissue diagnosis. If surgery is planned, the findings of EUS-FNA/B can change the selected surgical procedure. Clinically important SETs, such as leiomyomas, GISTs, schwannomas, heterotopic pancreas, SET-like carcinomas, and metastatic tumors can have a hypoechoic echo pattern and similar endoscopic features. For the accurate diagnosis of these tumors, it is important to obtain a sufficient amount of tissue so that the structure of the lesion can be sufficiently assessed and to enable immunohistochemical examination. Recent guidelines have recommended deciding the timing of tissue sampling based on the size of the tumor and high-risk features for malignancy on endoscopy and EUS (Table 1).

\section{Tumor size}

Current guidelines have suggested $2 \mathrm{~cm}$ as the cutoff diameter of SETs for further evaluation or periodic surveillance, despite the previously recommended cutoff of $3 \mathrm{~cm}$ by the

Table 1. Features of Gastric Subepithelial Tumor Requiring Endoscopic Ultrasound-Guided Fine Needle Aspiration and Biopsy

\begin{tabular}{l}
\hline Malignant features on endoscopy \\
Large size $(\geq 2 \mathrm{~cm})$ \\
Ulceration \\
Irregular surface \\
Growth during follow-up \\
Malignant features on EUS \\
Echogenic foci $>3 \mathrm{~mm}$ \\
Cystic spaces $>4 \mathrm{~mm}$ \\
Irregular border \\
Adjacent lymph node
\end{tabular}

EUS, endoscopic ultrasound.
American Gastroenterological Association.-7 The European Society of Medical Oncology (ESMO) and the European Society of Gastrointestinal Endoscopy (ESGE) recommended EUS for SETs less than $2 \mathrm{~cm}$ in the esophagus, stomach, and duodenum followed by periodic surveillance. ${ }^{8,9}$ According to previous reports on the natural clinical course of small SETs, less than 2-3 cm in size, during 24-48 months of follow-up, there was no tumor-related death or a newly developed symptom related to disease progression, with only less than $8.5 \%$ of interval change in the tumor size. ${ }^{10,11}$ Another study reported that GISTs less than $2 \mathrm{~cm}$ do not metastasize if the number of mitoses is less than 5/50 high-power fields (HPFs). In addition, despite the high rate of metastases of GISTs with a mitotic count exceeding 5/50 HPFs in the GI tract, small gastric GISTs showed exceptional results without increased metastases rates. ${ }^{12}$ As asymptomatic SETs less than $2 \mathrm{~cm}$ harbor a very low risk of progression and usually show a benign clinical course, these tumors can be followed up periodically at intervals of 6 months-2 years. ${ }^{13,14}$ However, SETs showing growth in size during the follow-up period should be further evaluated with tissue sampling for pathologic diagnosis, regardless of the size.

\section{High-risk features on endoscopy and EUS}

Gastric SETs, particularly mesenchymal tumors, such as GISTs, leiomyomas, or schwannomas, show similar findings on endoscopy and EUS. Therefore, efforts have been made to determine specific risk features that distinguish these tumors. Gastric SETs with high-risk features on endoscopy and EUS may have a clinically malignant potential. Biopsy or resection of these tumors is required to determine the long-term prognosis.

Large size $(\geq 2 \mathrm{~cm})$, ulceration, irregular surface, and growth during the follow-up are significant features indicating potentially malignant GISTs. ${ }^{7,15-17}$ As gastric neuroendocrine tumors and gastric carcinomas resembling submucosal tumors (by virtue of occurring in the submucosa) often present with a mucosal ulceration or an irregular margin, SETs with an ulceration or a depressed surface are recommended for biopsy to obtain a definite diagnosis. ${ }^{7}$ Current guidelines suggest further evaluation, including CT scan, EUS, or EUS-FNA/B for SETs with malignant features on endoscopy.

The Japan Gastroenterological Endoscopy Society has identified high-risk lesions on EUS as those having an irregular border, internal heterogeneity, such as anechoic areas and echogenic foci, heterogeneous enhancement, and regional lymph node enlargement. ${ }^{15,18}$ The well-known EUS findings that generally cause suspicion of malignancy include (1) a tumor size greater than $4 \mathrm{~cm}$, (2) echogenic foci greater than $3 \mathrm{~mm}$, (3) cystic spaces greater than $4 \mathrm{~mm}$, (4) an irregular border, and (5) adjacent lymph node with malignant pattern 
(Fig. 1). ${ }^{18-23}$ The presence of at least two of the criteria from (1) to (4) predicts a malignant GIST with $80 \%-100 \%$ sensitivity, ${ }^{19}$ whereas the combined presence of two of the criteria from (3) to (5) has a positive predictive value of $100 \%$ for a malignant or borderline gastrointestinal stromal cell tumor. ${ }^{18}$ The optimal size for predicting malignant GISTs was reported to be 35 $\mathrm{mm}$, with a sensitivity and specificity of $92.3 \%$ and $78.8 \%$, respectively. ${ }^{24}$ The combinations of these several features enable narrowing down the possible diagnosis and allow identifying malignant lesions.

\section{DIAGNOSTIC YIELD}

Although EUS-FNA/B has the strength of having high sen-

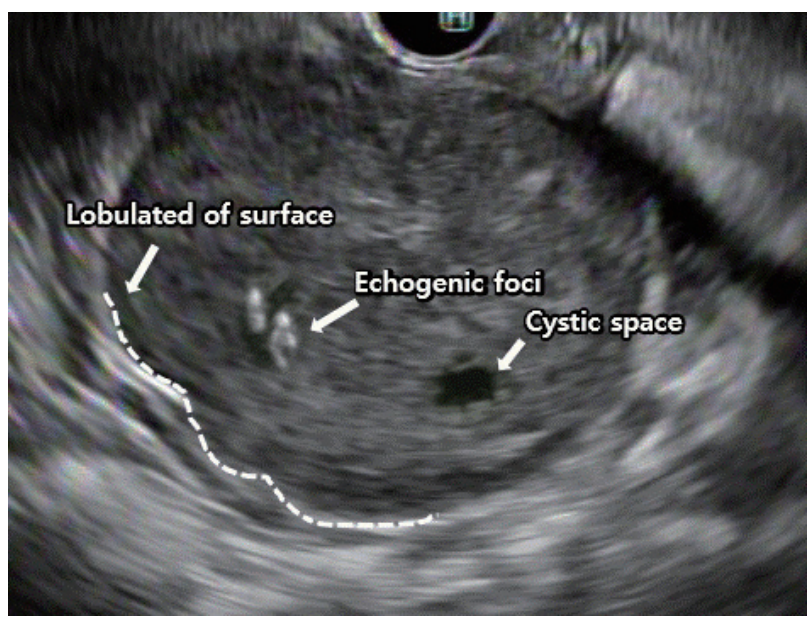

Fig. 1. Endoscopic ultrasound features suggestive of a malignant gastric subepithelial tumor. sitivity and high specificity, its sampling adequacy and diagnostic rates were reported to be only $74.5 \%-83.0 \%$ and $71.0 \%-$ $83.9 \%$, respectively. ${ }^{25-28}$ The diagnostic accuracy of EUS-FNA/B is influenced by many factors, including the nature of the target lesion, degree of technical difficulty of the procedure, size of the needle, number of needle passes, use of suction, use of a stylet in the needle assembly, special maneuvers to procure better-quality tissue, such as the fanning technique, availability of an on-site cytopathologist, and experience of the endosonographer (Table 2).

\section{Nature of the target lesion and patient}

Transesophageal and transgastric EUS-FNA/B with a straight scope position result in a higher diagnostic yield than does transduodenal EUS-FNA/B with an angulated scopetip position. ${ }^{29}$ The diagnostic yield is also influenced by the patient's age and the location of the tumor. A patient age of under 60 years and a lower third location of an SET are predictive factors of an inadequate tissue yield in EUS-FNA/ $\mathrm{B} .^{27}$ When the tumor size was divided into 2-cm intervals of $0-2,2-4$, and $\geq 4 \mathrm{~cm}$, the diagnostic rates were $71 \%, 86 \%$, and $100 \%$, respectively. ${ }^{28}$

\section{FNA needle}

Needle choice is based on the consideration of the following: the ability to acquire adequate cellular material for accurate diagnosis, flexibility to approach the tumor, and minimal complications. Currently, needles for EUS-FNA are available in 4 sizes, including 19, 20, 22, and 25 gauge (Table 3). A 19-gauge needle with its larger bore is considered to acquire larger tissue samples and to provide better cellularity than that of fine needles. ${ }^{30}$ However, because of the possibility of

Table 2. Studies on Factors Influencing Result of Endoscopic Ultrasound-Guided Fine Needle Aspiration and Biopsy

\begin{tabular}{|c|c|c|c|}
\hline Variable & Study & Location $(n)$ & Results \\
\hline \multirow[t]{7}{*}{ Needle size } & Hoda et al. ${ }^{25}$ & Stomach (112) & Diagnostic yield: $22 \mathrm{~g}=62 \%$ diagnostic, $22 \%$ suspicious \\
\hline & Mekky et al. ${ }^{26}$ & Stomach (141) & Diagnostic yield: $22 \mathrm{~g}=43 \%$ diagnostic, $39 \%$ suspicious \\
\hline & Suzuki et al. ${ }^{27}$ & Stomach (47) & Diagnostic yield: $22 \mathrm{~g}=74.5 \%$ \\
\hline & Larghi et al. ${ }^{30}$ & $\begin{array}{l}\text { Stomach (96), esophagus, (13) duodenum (10), } \\
\text { rectum (2) }\end{array}$ & Adequate sample: $19 \mathrm{~g}=93.4 \%$ \\
\hline & Eckardt et al. ${ }^{31}$ & Stomach (46) & Diagnostic yield: $19 \mathrm{~g}=52 \%$ \\
\hline & Watson et al. ${ }^{32}$ & Stomach (55), esophagus (7), duodenum (4) & Diagnostic yield: $22 \mathrm{~g}=64 \%, 19 \mathrm{~g}=79 \%(p=0.345)$ \\
\hline & Imazu et al. ${ }^{36}$ & Stomach (20) & Accuracy: $25 \mathrm{~g}=60 \%, 22 \mathrm{~g}=80 \%$ ( $p=$ not significant $)$ \\
\hline \multirow[t]{2}{*}{ Needle pass } & Hoda et al. ${ }^{25}$ & Stomach (70), esophagus (34), duodeum (8) & Diagnostic yield: mean needle pass $5.3=83.9 \%$ \\
\hline & Kim et al. ${ }^{39}$ & Stomach (30), esophagus (4), duodenum (2) & Adequate sample: pass $2=80.6 \%$, Pass $3=79.4 \%$ \\
\hline ROSE & Tamura et al. ${ }^{64}$ & Stomach (25), duodenum (6), rectum (1) & $\begin{array}{l}\text { Diagnostic accuracy: rose }=100 \%, \text { no rose }=80 \% \\
(p=0.03)\end{array}$ \\
\hline
\end{tabular}

ROSE, rapid on-site evaluation. 
Table 3. Endoscopic Ultrasound-Guided Fine Needle Aspiration Needles

\begin{tabular}{|c|c|c|}
\hline Manufacturer/Model & Needle diameter $(\mathbf{G})$ & Intended sample \\
\hline \multicolumn{3}{|l|}{ Boston Scientific, USA } \\
\hline Expect $^{\mathrm{TM}}$ & $25,22,19 \mathrm{G}^{\mathrm{a})}$ & Aspirated cells \\
\hline Expect $^{\mathrm{TM}} 19$ Flex & 19 G Flex & Aspirated cells \\
\hline Acquire $^{\mathrm{TM}}$ & $25,22 \mathrm{G}$ & Core biopsy \\
\hline \multicolumn{3}{|c|}{ Cook Medical, Ireland \& USA } \\
\hline EchoTip $^{\circledR}$ Ultra & $25,22,19 \mathrm{G}$ & Aspirated cells \\
\hline EchoTip $^{\circledR}$ ProCore ${ }^{\mathrm{TM}}$ & $25,22,20,19 \mathrm{G}$ & Core biopsy \\
\hline \multicolumn{3}{|l|}{ Finemedix, Korea } \\
\hline ClearTip $^{\circledR}$ (A type) & $25,22,19 \mathrm{G}$ & Aspirated cells \\
\hline ClearTip $^{\circledR}$ (B type) & $25,22,19 \mathrm{G}$ & Core biopsy \\
\hline \multicolumn{3}{|l|}{ Medi-Globe, Germany } \\
\hline SonoTip ${ }^{\mathbb{R}}$ Pro Control & $25,22,19 \mathrm{G}$ & Aspirated cells \\
\hline \multicolumn{3}{|l|}{ Olympus, Japan ${ }^{\text {b) }}$} \\
\hline EZ-shot 3 plus & $22,19 \mathrm{G}$ & Aspirated cells + Core biopsy \\
\hline
\end{tabular}

a) $19 \mathrm{G}$ needle have been used to acquire core biopys samples; ${ }^{\text {b) }}$ Compatible only with Olympus scopes.

blood dilution of the specimen and reduced maneuverability in areas with sharp angulation, a large-bore needle does not necessarily lead to favorable outcomes with a higher diagnostic yield. ${ }^{31,32}$ Therefore, for tumors located in the fundus or antrum, a 22-gauge needle is often preferred because of its maneuverability in angulated areas. In addition, lesion types such as GISTs and lymphomas may need a large-bore needle because their diagnosis requires specimens with preserved tissue architecture. ${ }^{33,34}$ Meanwhile, a recent meta-analysis and systemic review showed no significant difference in the accuracy and complication rates between the 22-gauge needle and the 25-gauge needle, with the 25-gauge needle only showing a small advantage in acquiring an adequate sample. ${ }^{35,36}$ Recently, a new generation of flexible 19-gauge core biopsy needles has been introduced, which has shown promising results for lesions requiring a transduodenal approach. ${ }^{37}$ A Korean EUS study group compared a 22-gauge aspiration needle with a 22-gauge biopsy needle for sampling SETs, and reported that the EUS-FNB group had significantly higher yields of histological core samples and higher diagnostic sufficiency rates. ${ }^{38}$ In addition, EUS-FNB with a 20-gauge ProCore needle is a technically feasible and effective modality for histopathologic diagnosis of gastrointestinal SETs, providing adequate core samples with fewer needle passes. ${ }^{39}$

\section{Number of needle passes}

The number of needle passes required to achieve the highest diagnostic yield vary widely. The presence of an on-site cytopathologist is the main factor influencing the number of needle passes, in addition to the characteristics of the lesion (cystic or solid) and its location. ${ }^{40}$ In multivariate analyses, although the number of needle passes was not found to be a significant factor for the adequacy of collected specimens, 25,26 gastric SETs have shown an $83 \%$ sample adequacy with 2.5 needle passes, a diagnostic accuracy of $83.9 \%$ with 5.3 needle passes, and the plateau of diagnostic accuracy was reached with $2.5-4$ needle passes. ${ }^{25,26,41}$

\section{Use of suction}

The role of suction during EUS-FNA is still controversial. However, depending on the nature of the target lesion, the effect of suction utilization may be different. In vascular-rich lesions, such as lymph nodes, suction may result in blood dilution, thus yielding poor-quality samples. A randomized controlled study reported that the use of suction resulted in better cellularity, more blood in specimens, and no improvement in diagnostic yield. ${ }^{42}$ On the contrary, in fibrotic lesions or solid masses, suction may enable acquiring adequate samples. ${ }^{43-45}$ In several studies, cellularity, accuracy, and sensitivity were higher in the suction group than in the non-suction group. ${ }^{46,47}$ However, in another randomized controlled study, suction did not improve the diagnostic yield of FNA. ${ }^{47}$ A previous study on the suction method recommended the use of suction in lesions suspected to be mesenchymal tumors, considering the reported cohesiveness of mesenchymal tissue. ${ }^{48}$

\section{Stylet}

The use of a stylet has been proposed to optimize the diag- 
nostic yield of tissue acquisition in solid lesions. This method prevents the needle tip from being contaminated or blocked by a plug of gastric wall tissue before reaching the target lesion, thereby increasing the ability of tissue aspiration and improving the quality of the specimen. However, randomized trials have demonstrated that the use of a stylet during EUSFNA does not improve the diagnostic yield and cellularity. ${ }^{49-51}$ The use of a stylet is not recommended considering the labor used to reinsert the stylet and the prolongation of the procedure time. In addition, insertion and retrieval of the stylet may be difficult in angulated areas because of the bending of the endoscope. Furthermore, re-use of the stylet during the second and third tissue acquisitions increases the risk of needle stick injury. However, most investigators use a stylet during puncture for removing the aspirated sample from the slide.

\section{Fanning}

Fanning is a technique for acquiring specimens from multiple areas through a single puncture, in which the needle is moved back and forth in a fan shape by using the elevator and the up/down dial control of the endoscope. The fanning method has been used to improve the diagnostic yield, particularly in cancerous tumors with a necrotic center. In a study on pancreatic masses, fanning resulted in fewer numbers of passes needed to obtain a diagnosis, with a high first-pass diagnostic rate. ${ }^{52}$ Although SET is often not a cancerous lesion having a necrotic portion and may be firm when located in the muscular layer, the fanning technique is still expected to increase the diagnostic rate by collecting tissue from multiple sites of the tumor.

\section{On-site cytopathologist}

The presence of an on-site cytopathologist is considered to be a key factor for the diagnostic sensitivity in EUS-FNA, ${ }^{53}$ as it improves the diagnostic yield, increases the adequacy of samples, and reduces the number of needle passes. ${ }^{54-59}$ Previous studies have reported that the presence of an on-site cytopathologist increased the rates of sample adequacy by $10 \%-29 \%$, resulting in a $10 \%-15 \%$ increase in the diagnostic rate. ${ }^{45,60,61}$ However, many hospitals do not have an available on-site cytopathologist. In a recent study conducted to overcome these limitations, gross evaluation of the adequacy of samples, such as macroscopic on-site quality evaluation (MOSE) or rapid on-site evaluation (ROSE), by an EUS examiner resulted in improvements in the diagnostic accuracy of EUS-FNA. ${ }^{62-65}$ By using MOSE, when the presence of a macroscopic visible core of more than $4 \mathrm{~mm}$ was considered to indicate an appropriate specimen, the macroscopic evaluation failed in only $7 \%$ of cytology samples and in $13.5 \%$ of histolo- gy samples. ${ }^{63}$ According to the ROSE study, endosonographers who underwent extensive training in processing techniques with a pathologist tended to need fewer needle passes than those who performed FNA without ROSE. According to these reports, gross evaluation of the adequacy of samples by endosonographers may be sufficient in deciding the number of needle passes when no cytopathologists are available.

\section{CONCLUSIONS}

EUS-FNA/B is a minimally invasive and effective diagnostic method that plays an important role in the diagnosis of gastrointestinal SETs, which, in turn, have a decisive impact on making appropriate treatment choices. Although the tumor size that requires EUS-FNA/B has not been established, current guidelines have suggested that tumors $>2 \mathrm{~cm}$ and having malignant features, such as ulceration and an irregular border, require a pathologic diagnosis through EUS-FNA/B. Recently, new-generation flexible needles with improved diagnostic yield have been introduced. According to the characteristics of the SETs, a suitable FNA/B needle should be used and various methods such as the use of a stylet, the suction method, and the fanning technique should be appropriately employed to improve the diagnostic yield of EUS-FNA.

\section{Conflicts of Interest}

The authors have no financial conflicts of interest.

\section{REFERENCES}

1. Hedenbro JL, Ekelund M, Wetterberg P. Endoscopic diagnosis of submucosal gastric lesions. The results after routine endoscopy. Surg Endosc 1991;5:20-23.

2. Lee JH, Lee HL, Ahn YW, et al. Prevalence of gastric subepithelial tumors in Korea: a single center experience. Korean J Gastroenterol 2015;66:274-276.

3. Landi B, Palazzo L. The role of endosonography in submucosal tumours. Best Pract Res Clin Gastroenterol 2009;23:679-701.

4. Ji JS, Lee BI, Choi KY, et al. Diagnostic yield of tissue sampling using a bite-on-bite technique for incidental subepithelial lesions. Korean J Intern Med 2009;24:101-105.

5. Cho JW. Current guidelines in the management of upper gastrointestinal subepithelial tumors. Clin Endosc 2016;49:235-240.

6. Nishida T, Blay JY, Hirota S, Kitagawa Y, Kang YK. The standard diagnosis, treatment, and follow-up of gastrointestinal stromal tumors based on guidelines. Gastric Cancer 2016;19:3-14.

7. Nishida T, Hirota S, Yanagisawa A, et al. Clinical practice guidelines for gastrointestinal stromal tumor (GIST) in Japan: English version. Int J Clin Oncol 2008;13:416-430.

8. Casali PG, Abecassis N, Bauer S, et al. Gastrointestinal stromal tumours: ESMO-EURACAN clinical practice guidelines for diagnosis, treatment and follow-up. Ann Oncol 2018;29(Suppl 4):iv68-iv78.

9. Dumonceau JM, Deprez PH, Jenssen C, et al. Indications, results, and clinical impact of endoscopic ultrasound (EUS)-guided sampling in gas- 
troenterology: European Society of Gastrointestinal Endoscopy (ESGE) clinical guideline - updated January 2017. Endoscopy 2017;49:695-714.

10. Kim MY, Jung HY, Choi KD, et al. Natural history of asymptomatic small gastric subepithelial tumors. J Clin Gastroenterol 2011;45:330-336.

11. Yegin EG, Kani T, Banzragch M, Kalayci C, Bicakci E, Duman DG. Survival in patients with hypoechoic muscularis propria lesions suggestive of gastrointestinal stromal tumors in gastric wall. Acta Gastroenterol Belg 2015;78:12-17.

12. Miettinen M, Lasota J. Gastrointestinal stromal tumors: pathology and prognosis at different sites. Semin Diagn Pathol 2006;23:70-83.

13. Agaimy A, Wünsch $\mathrm{PH}$, Hofstaedter F, et al. Minute gastric sclerosing stromal tumors (GIST tumorlets) are common in adults and frequently show c-KIT mutations. Am J Surg Pathol 2007;31:113-120.

14. Kawanowa K, Sakuma Y, Sakurai S, et al. High incidence of microscopic gastrointestinal stromal tumors in the stomach. Hum Pathol 2006;37:1527-1535

15. Nishida T, Kawai N, Yamaguchi S, Nishida Y. Submucosal tumors: comprehensive guide for the diagnosis and therapy of gastrointestinal submucosal tumors. Dig Endosc 2013;25:479-489.

16. Demetri GD, von Mehren M, Antonescu CR, et al. NCCN task force report: update on the management of patients with gastrointestinal stromal tumors. J Natl Compr Canc Netw 2010;8 Suppl 2:S1-S41; quiz S42-S44.

17. Yegin EG, Duman DG. Small EUS-suspected gastrointestinal stromal tumors of the stomach: an overview for the current state of management. Endosc Ultrasound 2016;5:69-77.

18. Palazzo L, Landi B, Cellier C, Cuillerier E, Roseau G, Barbier JP. Endosonographic features predictive of benign and malignant gastrointestinal stromal cell tumours. Gut 2000;46:88-92.

19. Chak A, Canto MI, Rösch T, et al. Endosonographic differentiation of benign and malignant stromal cell tumors. Gastrointest Endosc 1997;45:468-473.

20. Brand B, Oesterhelweg L, Binmoeller KF, et al. Impact of endoscopic ultrasound for evaluation of submucosal lesions in gastrointestinal tract. Dig Liver Dis 2002;34:290-297.

21. Rösch T, Kapfer B, Will U, et al. Accuracy of endoscopic ultrasonography in upper gastrointestinal submucosal lesions: a prospective multicenter study. Scand J Gastroenterol 2002;37:856-862.

22. Ando N, Goto H, Niwa Y, et al. The diagnosis of GI stromal tumors with EUS-guided fine needle aspiration with immunohistochemical analysis. Gastrointest Endosc 2002;55:37-43.

23. Okubo K, Yamao K, Nakamura T, et al. Endoscopic ultrasound-guided fine-needle aspiration biopsy for the diagnosis of gastrointestinal stromal tumors in the stomach. J Gastroenterol 2004;39:747-753.

24. Kim GH, Park DY, Kim S, et al. Is it possible to differentiate gastric GISTs from gastric leiomyomas by EUS? World J Gastroenterol 2009;15:3376-3381.

25. Hoda KM, Rodriguez SA, Faigel DO. EUS-guided sampling of suspected GI stromal tumors. Gastrointest Endosc 2009;69:1218-1223.

26. Mekky MA, Yamao K, Sawaki A, et al. Diagnostic utility of EUS-guided FNA in patients with gastric submucosal tumors. Gastrointest Endosc 2010;71:913-919.

27. Suzuki T, Arai M, Matsumura T, et al. Factors associated with inadequate tissue yield in EUS-FNA for gastric SMT. ISRN Gastroenterol 2011;2011:619128.

28. Akahoshi K, Sumida Y, Matsui N, et al. Preoperative diagnosis of gastrointestinal stromal tumor by endoscopic ultrasound-guided fine needle aspiration. World J Gastroenterol 2007;13:2077-2082.

29. Haseeb A, Taylor LJ, Adler DG. Comparing endoscopic ultrasoundguided core biopsies of solid pancreatic and extrapancreatic lesions: a large single-operator experience with a new fine-needle biopsy needle. Ann Gastroenterol 2018;31:742-746.

30. Larghi A, Fuccio L, Chiarello G, et al. Fine-needle tissue acquisition from subepithelial lesions using a forward-viewing linear echoendoscope. Endoscopy 2014;46:39-45.
31. Eckardt AJ, Adler A, Gomes EM, et al. Endosonographic large-bore biopsy of gastric subepithelial tumors: a prospective multicenter study. Eur J Gastroenterol Hepatol 2012;24:1135-1144.

32. Watson RR, Binmoeller KF, Hamerski CM, et al. Yield and performance characteristics of endoscopic ultrasound-guided fine needle aspiration for diagnosing upper GI tract stromal tumors. Dig Dis Sci 2011;56:17571762.

33. DeWitt J, Emerson RE, Sherman S, et al. Endoscopic ultrasound-guided Trucut biopsy of gastrointestinal mesenchymal tumor. Surg Endosc 2011;25:2192-2202.

34. Amador-Ortiz C, Chen L, Hassan A, et al. Combined core needle biopsy and fine-needle aspiration with ancillary studies correlate highly with traditional techniques in the diagnosis of nodal-based lymphoma. Am J Clin Pathol 2011;135:516-524.

35. Affolter KE, Schmidt RL, Matynia AP, Adler DG, Factor RE. Needle size has only a limited effect on outcomes in EUS-guided fine needle aspiration: a systematic review and meta-analysis. Dig Dis Sci 2013;58:10261034.

36. Imazu $\mathrm{H}$, Uchiyama $\mathrm{Y}$, Kakutani $\mathrm{H}$, et al. A prospective comparison of EUS-guided FNA using 25-gauge and 22-gauge needles. Gastroenterol Res Pract 2009;2009:546390.

37. Varadarajulu S, Bang JY, Hebert-Magee S. Assessment of the technical performance of the flexible 19-gauge EUS-FNA needle. Gastrointest Endosc 2012;76:336-343.

38. Kim GH, Cho YK, Kim EY, et al. Comparison of 22-gauge aspiration needle with 22-gauge biopsy needle in endoscopic ultrasonography-guided subepithelial tumor sampling. Scand J Gastroenterol 2014;49:347-354.

39. Kim DH, Kim GH, Cho CM, et al. Feasibility of a 20-gauge ProCore needle in EUS-guided subepithelial tumor sampling: a prospective multicenter study. BMC Gastroenterol 2018;18:151.

40. Petrone MC, Arcidiacono PG. Basic technique in endoscopic ultrasound-guided fine needle aspiration for solid lesions: how many passes? Endosc Ultrasound 2014;3:22-27.

41. Pellisé Urquiza M, Fernández-Esparrach G, Solé M, et al. Endoscopic ultrasound-guided fine needle aspiration: predictive factors of accurate diagnosis and cost-minimization analysis of on-site pathologist. Gastroenterol Hepatol 2007;30:319-324.

42. Wallace MB, Kennedy T, Durkalski V, et al. Randomized controlled trial of EUS-guided fine needle aspiration techniques for the detection of malignant lymphadenopathy. Gastrointest Endosc 2001;54:441-447.

43. Santos JE, Leiman G. Nonaspiration fine needle cytology. Application of a new technique to nodular thyroid disease. Acta Cytol 1988;32:353-356.

44. Kinney TB, Lee MJ, Filomena CA, et al. Fine-needle biopsy: prospective comparison of aspiration versus nonaspiration techniques in the abdomen. Radiology 1993;186:549-552.

45. Polkowski M, Larghi A, Weynand B, et al. Learning, techniques, and complications of endoscopic ultrasound (EUS)-guided sampling in gastroenterology: European Society of Gastrointestinal Endoscopy (ESGE) technical guideline. Endoscopy 2012;44:190-206.

46. Lee JK, Choi JH, Lee $\mathrm{KH}$, et al. A prospective, comparative trial to optimize sampling techniques in EUS-guided FNA of solid pancreatic masses. Gastrointest Endosc 2013;77:745-751.

47. Puri R, Vilmann P, Săftoiu A, et al. Randomized controlled trial of endoscopic ultrasound-guided fine-needle sampling with or without suction for better cytological diagnosis. Scand J Gastroenterol 2009;44:499504.

48. Eckardt AJ, Jenssen C. Current endoscopic ultrasound-guided approach to incidental subepithelial lesions: optimal or optional? Ann Gastroenterol 2015;28:160-172.

49. Sahai AV, Paquin SC, Gariépy G. A prospective comparison of endoscopic ultrasound-guided fine needle aspiration results obtained in the same lesion, with and without the needle stylet. Endoscopy 2010;42:900903.

50. Rastogi A, Wani S, Gupta N, et al. A prospective, single-blind, random- 
ized, controlled trial of EUS-guided FNA with and without a stylet. Gastrointest Endosc 2011;74:58-64

51. Wani S, Gupta N, Gaddam S, et al. A comparative study of endoscopic ultrasound guided fine needle aspiration with and without a stylet. Dig Dis Sci 2011;56:2409-2414.

52. Bang JY, Magee SH, Ramesh J, Trevino JM, Varadarajulu S. Randomized trial comparing fanning with standard technique for endoscopic ultrasound-guided fine-needle aspiration of solid pancreatic mass lesions. Endoscopy 2013;45:445-450.

53. Varadarajulu S, Fockens P, Hawes RH. Best practices in endoscopic ultrasound-guided fine-needle aspiration. Clin Gastroenterol Hepatol 2012;10:697-703

54. Collins BT, Murad FM, Wang JF, Bernadt CT. Rapid on-site evaluation for endoscopic ultrasound-guided fine-needle biopsy of the pancreas decreases the incidence of repeat biopsy procedures. Cancer Cytopathol 2013;121:518-524.

55. Schmidt RL, Witt BL, Matynia AP, Barraza G, Layfield LJ, Adler DG. Rapid on-site evaluation increases endoscopic ultrasound-guided fine-needle aspiration adequacy for pancreatic lesions. Dig Dis Sci 2013;58:872-882

56. Klapman JB, Logrono R, Dye CE, Waxman I. Clinical impact of onsite cytopathology interpretation on endoscopic ultrasound-guided fine needle aspiration. Am J Gastroenterol 2003;98:1289-1294.

57. Jhala NC, Jhala DN, Chhieng DC, Eloubeidi MA, Eltoum IA. Endoscopic ultrasound-guided fine-needle aspiration. A cytopathologist's perspective. Am J Clin Pathol 2003;120:351-367.

58. Iglesias-Garcia J, Dominguez-Munoz JE, Abdulkader I, et al. Influence of on-site cytopathology evaluation on the diagnostic accuracy of en- doscopic ultrasound-guided fine needle aspiration (EUS-FNA) of solid pancreatic masses. Am J Gastroenterol 2011;106:1705-1710.

59. Alsohaibani F, Girgis S, Sandha GS. Does onsite cytotechnology evaluation improve the accuracy of endoscopic ultrasound-guided fine-needle aspiration biopsy? Can J Gastroenterol 2009;23:26-30.

60. Storch I, Jorda M, Thurer R, et al. Advantage of EUS Trucut biopsy combined with fine-needle aspiration without immediate on-site cytopathologic examination. Gastrointest Endosc 2006;64:505-511.

61. Turhan N, Aydog G, Ozin Y, Cicek B, Kurt M, Oguz D. Endoscopic ultrasonography-guided fine-needle aspiration for diagnosing upper gastrointestinal submucosal lesions: a prospective study of 50 cases. Diagn Cytopathol 2011;39:808-817.

62. Iwashita T, Yasuda I, Mukai T, et al. Macroscopic on-site quality evaluation of biopsy specimens to improve the diagnostic accuracy during EUS-guided FNA using a 19-gauge needle for solid lesions: a single-center prospective pilot study (MOSE study). Gastrointest Endosc 2015;81:177-185.

63. Moller K, Papanikolaou IS, Toermer T, et al. EUS-guided FNA of solid pancreatic masses: high yield of 2 passes with combined histologic-cytologic analysis. Gastrointest Endosc 2009;70:60-69.

64. Tamura T, Yamashita Y, Ueda K, et al. Rapid on-site evaluation by endosonographers during endoscopic ultrasonography-guided fine-needle aspiration for diagnosis of gastrointestinal stromal tumors. Clin Endosc 2017;50:372-378

65. Cermak TS, Wang B, DeBrito P, Carroll J, Haddad N, Sidawy MK. Does on-site adequacy evaluation reduce the nondiagnostic rate in endoscopic ultrasound-guided fine-needle aspiration of pancreatic lesions? Cancer Cytopathol 2012;120:319-325. 